\title{
NEW WORLD
}

\section{No Boom for Atomic Energy}

The Joint Committee on Atomic Energy, the watchdog of the Atomic Energy Commission, has deserved its reputation with the commission's firmest friends by recommending a budget authorization which is $\$ 7.7$ million more than the $\$ 2,283$ million for which the Administration had asked in February. Without dissent, the budget passed through the Senate and the House of Representatives a week ago, although it remains to be seen whether this larger sum of money will actually be appropriated for the coming year and whether, if it is, the AEC will be allowed to spend it. Those who will have been impressed with the evidence given to the committee about the effect of some of the Administration's policies on the ability of the AEC to support basic research in the physical sciences will no doubt be disappointed that the joint committee has nothing to add to these items in the Administration's budget.

If there is no extra money, however, the committee does have something to say about the consequences of the Atomic Energy Commission's new attitude to basic research. In the year ahead, the commission's expenditure on physical research will be $\$ 274$ million, a decrease of $\$ 3.75$ million from the preceding year. In addition, the AEC has asked to spend in the coming financial year a total of $\$ 119$ million on capital projects, chief among which is the $200 \mathrm{GeV}$ accelerator-now to be made capable of accelerating protons to $500 \mathrm{GeV}$. The joint committee says that the decision during the eoming year to "start to phase out" the proton accelerator operated jointly by Princeton University and the University of Pennsylvania and which has been, according to the joint committee, the mainstay for high energy research for fifteen university groups in the past five years, is most disturbing. The joint committee goes on to say that the shutdown should be postponed at least until the universities can find the money to keep on operating the accelerator, in which light it is more than a little surprising that the joint committee offers no extra money.

In other parts of the physical research programme supported by the AEC, the committce says it is concerned that there is nothing in the 1971 budget for the building of high encrgy particle storage rooms comparable with those at CERN, saying that the result will be that increasing numbers of American scientists will try to carry out work at facilities abroad, to the detriment of what they undertake in the United States. One of the fields in which the AEC proposes to increase its rate of expenditure is in medium energy physics, chiefly in connexion with the Los Alamos meson physics facility, but the committee takes the view that the plan to build into the machine facilities for biomedical research some time in the futurc should be paid for with other funds. Without recommending extra money, the committee has also shaken its head over the reduction of expenditure on low energy physics, chiefly by the shutting down of Van de Graaff accelerators at a number of universities. In spite of the enthusiasm of the AEC for thermonuclear research based on variations of the Russian Tokamak devices described in the past year, the joint committee believes that there is still much to be gained from a study of other types of thermonuclear machines and hence it has lopped off $\$ 1$ million from the AEC's request.

The joint committee has dealt with other parts of the AEC's programme for 1971 with similar care. One of its more vigorous decisions has been to ask the AEC to spend more effort on the development of liquid metal fast breeder reactors, which is "of the highest priority". The joint committec says that it would like to see more interest in industrially sponsored reactor projects and fears that the amount of money allocated for helping such work along is insufficient. In the coming year, the AEC is planning to spend $\$ 43$ million on liquid metal fast breeder reactors, mostly at its own establishments, but something like $\$ 7$ million is also being spent on the definition of prototype reactors. The joint com. mittee is doubtful of the significance of this work and has attached to the authorization bill a requirement that the Atomic Energy Commission should give it 45 days in which to consider and approve of proposals for collaboration with industrial companies for the building of experimental reactors. In general, however, the committee does urge that the AEC should build itself a breeder demonstration plant without delay.

The other amendments to the Administration's request for funds recommended by the joint committee spring from its belief that more needs to be done to build up stocks of fissile material for military as well as civil purposes. In particular, the committee quarrels with the AEC's proposal to close one of the two reactors at Richland, Washington, which has been used for the manufacture of plutonium for the best part of two decades; it fears that the remaining military reactorsone at Richland, two at Hanford and three at Savannah River-would not be able to meet a sudden increase in the demand for nuclear explosives that might arise from the antiballistic missile programme now under way. It also asks that the AEC should be allowed to begin work on what is called the Cascade Improvement Program by means of which it has been suggested that the output of enriched uranium from gascous diffusion plants could be substantially increased. One of the committee's anxieties is that at the present level of operations, it will be hard for the US Government to honour its promise that enrichment services will be available to all qualified customers, in the United States and elsewhere, at a reasonably low cost.

Much of the joint committee's commentary on the AEC's proposals for 1971 is linked with the current preoccupation with the quality of the environment. Several parts of the proposed budget have been increased by modest sums of money. 'Thus the committee urges the expenditure of an extra $\$ 140$ on the food irradiation programme, chiefly so that the commission can carry out more careful studies of the mutagenicity of irradiated foods before applying to the Food and Drug Administration for permission to use them experimentally. 